\title{
Thyroid disorders in patients with abnormal uterine bleeding in tertiary care hospital in Chengalpattu district
}

\author{
S. Tamilarasi*, S. N. S. Minnalkodi, Geetha Prasad
}

\begin{abstract}
Department of Obstetrics and Gynecology, Karpaga Vinayaga Institute of Medical Sciences and Research Centre, Chinna Kolambakkam, Tamil Nadu, India
\end{abstract}

Received: 24 June 2020

Revised: 25 July 2020

Accepted: 29 July 2020

\author{
*Correspondence: \\ Dr. S. Tamilarasi, \\ E-mail: doc.tamil2015@gmail.com
}

Copyright: () the author(s), publisher and licensee Medip Academy. This is an open-access article distributed under the terms of the Creative Commons Attribution Non-Commercial License, which permits unrestricted non-commercial use, distribution, and reproduction in any medium, provided the original work is properly cited.

\begin{abstract}
Background: A relationship between the thyroid gland and the gonads is suggested by far more frequent occurrence of thyroid disorders in women than in men by clinical appearance of goiter during pregnancy, puberty, and menopause. Aim of this study was to determine the association between menstrual irregularities and thyroid dysfunction. To analyse the pattern of menstrual dysfunction among women with a thyroid disorder.

Methods: This cross-sectional study was done in Karpaga Vinayaga Institute of Medical Sciences and Research Center - obstetrics and gynecology OPD. Over 6 months in the year 2019. 100 women who presented with abnormal uterine bleeding with the below exclusion criteria. Detailed history taking with an emphasis on age, parity, infertility, and menstrual disorders. Evaluation by pelvic examination along with the general physical examination of those with menstrual complaints. Routine investigations like Hb, BT, CT, TLC, DLC, platelet count, and ABO-Rh in all. Then all patients were subjected to estimation of serum T3, T4, TSH with early morning samples.

Results: Menorrhagia presents in $39.4 \%$ of patients in the normal cohort and $63.6 \%$ in the thyroid dysfunction cohort. Hypomenorrhea presents in $4 \%$ normal cohort and $9.1 \%$ thyroid dysfunction cohort. Hypothyroidism presents in $7.27 \%$, subclinical hypothyroidism in $1.81 \%$, and hyperthyroidism in $0.92 \%$ of patients. Amenorrhoea presents in $16.2 \%$ of patients of the normal cohort and $9.1 \%$ of patients of thyroid dysfunction cohort. No statistical significance between amenorrhoea and thyroid dysfunction.32.3\% in the normal cohort and $36.4 \%$ in thyroid dysfunction cohort had a bulky uterus. No statistical association exists between thyroid dysfunction and uterine size. In a histopathological examination of the endometrium, $49.5 \%$ in the normal cohort and $54.5 \%$ thyroid dysfunction cohort reported as proliferative endometrium. Amenorrhoea; the significant association between abnormal uterine bleeding and thyroid disorder $(10 \%)$.

Conclusions: The significant association between abnormal uterine bleeding and thyroid disorder (10\%). It brings into focus the increased incidence of hypothyroidism among women with menorrhagia.
\end{abstract}

Keywords: Amenorrhoea, Body mass index, Sex hormone binding globulin, Thyroid stimulating hormone

\section{INTRODUCTION}

It has been long recognized that thyroid dysfunction may have profound effects on the female reproductive system. ${ }^{1}$ A relationship between the thyroid gland and the gonads is suggested by far more frequent occurrence of thyroid disorders in women than in men by clinical appearance of goiter during pregnancy, puberty, and menopause. $^{2}$ Thyroid disorders are 10 times more common in women than in men currently subclinical thyroid dysfunction is on the rising side than overt 
dysfunction. The effect of thyroid hormones is due to the direct metabolic effects on the gonads as well as indirectly through alterations in anterior pituitary hormones that control the sexual functions. ${ }^{3}$ Regular menstruation is a feature of contemporary society. Large family size, prolonged breastfeeding and reduced life expectancy limited the number of cycles experienced by women in the past. One of the common causes of women attending gynecology OPD is abnormal uterine bleeding constituting around 30 percentages. The majority of women who present with bleeding problems, no underlying abnormality could be made out. It is quite often this situation tackled with fractional curettage and finally the hysterectomy. ${ }^{4}$ AUB encompasses a wide spectrum of disorders such as reproductive tract diseases, systemic diseases, and iatrogenic causes. Thyroid dysfunction accounts for $30 \%-40 \%$ of cases in systemic disorders causing AUB. The goal of evaluation of AUB is to arrive at an accurate and clinically useful diagnosis most efficiently and cost-effectively possible. ${ }^{5}$ The thyroid function test is helpful in women presenting with AUB to detect subclinical conditions and provide an opportunity to treat the cause. This will avoid unnecessary hormonal treatment, surgery, and reduce patient morbidity. ${ }^{6}$

\section{METHODS}

This cross-sectional study was done in Karpaga Vinayaga Institute of Medical Sciences and Research Center obstetrics and gynecology OPD. Over 6 months in the year 2019. 100 women who presented with abnormal uterine bleeding with the below exclusion criteria. Detailed history taking with an emphasis on age, parity, infertility, and menstrual disorders. Evaluation by pelvic examination along with a general physical examination of those with menstrual complaints. Routine investigations like Hb, BT, CT, TLC, DLC, platelet count, and ABO-Rh in all. Then all patients were subjected to estimation of serum $\mathrm{T}_{3}, \mathrm{~T}_{4}, \mathrm{TSH}$ with early morning samples.

\section{Inclusion criteria}

The inclusion criteria of this study were the age group 1845 years, women with any of the following menstrual disturbances; menorrhagia, oligomenorrhoea, hypomenorrhea, polymenorrhea, amenorrhoea with no pelvic pathology. non-IUCD user, not using any hormonal preparations, with symptoms of thyroid dysfunction.

\section{Exclusion criteria}

Exclusion criteria of this study were the presence of palpable pelvic pathology - fibroids, polyp, cervical growth, history of bleeding diathesis and clotting abnormalities, patient on a drug like aspirin, heparin, antithyroid agents, and thyroxine. Known case of diabetes mellitus and systemic hypertension.
The patients selected for the study were counseled for undertaking the thyroid function test. Detailed menstrual history including length of the cycle, duration of the flow, and several pads usage was elicited and history regarding symptoms of hypothyroidism and hyperthyroidism also elicited. General examination including anemia, the height of the patients $(\mathrm{cm})$, the weight of the patient $(\mathrm{kg})$, thyroid enlargement was assessed. Body mass index was calculated using height and weight. Systemic examination was carried out. Abdominal examination, speculum, and pelvic examination are done to rule out other causes of abnormal uterine bleeding. Investigationscomplete blood count, platelet count, bleeding time, and clotting time, urine routine, blood sugar, RFT carried out. USG pelvis was done. Histopathological examination of endometrium performed by Pipelle's curette. Thyroid function test-Serum $\mathrm{TSH}$, free $\mathrm{T}_{3}$, and free $\mathrm{T}_{4}$ are compulsory. $5 \mathrm{ml}$ of blood was taken in dry glass contains without any anticoagulant. Fasting sample was taken, TSH assay was performed using the IRMA kit (Immuno radiometric assay).

\section{RESULTS}

Table 1, among 110 patients, $48(48.5 \%)$ belong to the normal cohort and $7(6.3 \%)$ belong to the thyroid dysfunction group in the age group 25-35 years. Out of 11 thyroid dysfunctions, the majority of 7 (63.6\%) were in the age group of 25-35 years.

Table 1: Age and thyroid dysfunction distribution.

\begin{tabular}{|lllll|}
\hline \multirow{2}{*}{$\begin{array}{l}\text { Age } \\
\text { (years) }\end{array}$} & \multicolumn{2}{l}{ Normal cohort } & \multicolumn{2}{l|}{$\begin{array}{l}\text { Thyroid } \\
\text { dysfunction cohort }\end{array}$} \\
\cline { 2 - 5 } No. of cases & \% & No. of cases & \% \\
\hline $\mathbf{1 8 - 2 4}$ & 25 & 25.3 & 2 & 18.2 \\
\hline $\mathbf{2 5 - 3 5}$ & 48 & 48.5 & 7 & 63.6 \\
\hline $\mathbf{3 6 - 4 5}$ & 26 & 26.3 & 2 & 18.2 \\
\hline
\end{tabular}

Table 2: Parity and thyroid dysfunction distribution.

\begin{tabular}{|lllll|}
\hline \multirow{2}{*}{ Parity } & \multicolumn{2}{l}{ Normal cohort } & \multicolumn{2}{l|}{$\begin{array}{l}\text { Thyroid } \\
\text { dysfunction cohort }\end{array}$} \\
& No. of cases & $\%$ & No. of cases & $\%$ \\
\hline Nulliparous & 4 & 4 & 1 & 9.1 \\
\hline P1L1 & 9 & 9.1 & 1 & 9.1 \\
\hline P2L2 & 54 & 54.5 & 6 & 54.5 \\
\hline P3L3 & 25 & 25.3 & 2 & 18.2 \\
\hline P4L4 & 7 & 7.1 & 1 & 9.1 \\
\hline
\end{tabular}

Table 2, multiparous (P2L2) 54.5\% in the normal cohort and $54.5 \%$ in the thyroid dysfunction cohort. No statistical significance between thyroid and non-thyroid samples concerning parity.

Table 3, menorrhagia presents in $39.4 \%$ of patients in the normal cohort and $63.6 \%$ in the thyroid dysfunction cohort. Hypomenorrhoea presents in $4 \%$ normal cohort and $9.1 \%$ thyroid dysfunction cohort. Out of 100 patients, 
menorrhagia in $41.81 \%$, oligomenorrhoea in $25.45 \%$, amenorrhoea in $15.45 \%$, hypomenorrhoea in $4.54 \%$, polymenorrhoea in $4.54 \%$ and menorrhagia in $8.18 \%$ of the AUB population. Hypothyroidism presents in $7.27 \%$, subclinical hypothyroidism in $1.81 \%$, and hyperthyroidism in $0.92 \%$ patients.

Table 3: AUB and thyroid dysfunction distribution.

\begin{tabular}{|lllll|}
\hline & Normal cohort & \multicolumn{2}{l}{$\begin{array}{l}\text { Thyroid } \\
\text { dysfunction } \\
\text { cohort }\end{array}$} \\
& $\begin{array}{l}\text { No. of } \\
\text { cases }\end{array}$ & $\%$ & $\begin{array}{l}\text { No. of } \\
\text { cases }\end{array}$ & $\%$ \\
\hline Menorrhagia & 39 & 39.4 & 7 & 63.6 \\
\hline Oligomenorrhoea & 28 & 28.3 & 0 & 0 \\
\hline Amenorrhoea & 16 & 16.2 & 1 & 9.1 \\
\hline Hypomenorrhoea & 4 & 4 & 1 & 9.1 \\
\hline Polymenorrhoea & 5 & 5.1 & 0 & 0 \\
\hline Menometorrhagia & 7 & 7.1 & 2 & 18.2 \\
\hline
\end{tabular}

Table 4, oligomenorrhoea presents in $28.3 \%$ of patients in the normal cohort and $18.2 \%$ of patients in the thyroid dysfunction cohort. No statistical significance between oligomenorrhoea and thyroid dysfunction. Chi-square $0.377, \mathrm{p}=0.75$ not significant.

Table 4: Oligomenorrhoea and thyroid dysfunction distribution.

\begin{tabular}{|lllll|}
\hline & Normal cohort & $\begin{array}{l}\text { Thyroid } \\
\text { dysfunction } \\
\text { cohort }\end{array}$ \\
& $\begin{array}{l}\text { No. of } \\
\text { cases }\end{array}$ & $\%$ & $\begin{array}{l}\text { No. of } \\
\text { cases }\end{array}$ & $\%$ \\
\hline Oligomenorrhoea & 28 & 28.3 & 2 & 18.2 \\
\hline Others & 71 & 71.7 & 9 & 81.8 \\
\hline
\end{tabular}

Table 5: Amenorrhoea and thyroid dysfunction.

\begin{tabular}{|lllll|}
\hline & Normal cohort & $\begin{array}{l}\text { Thyroid } \\
\text { dysfunction } \\
\text { cohort }\end{array}$ \\
& $\begin{array}{l}\text { No. of } \\
\text { cases }\end{array}$ & $\%$ & $\begin{array}{l}\text { No. of } \\
\text { cases }\end{array}$ & $\%$ \\
\hline Amenorrhoea & 16 & 16.2 & 1 & 9.1 \\
\hline Others & 83 & 83.8 & 10 & 90.9 \\
\hline
\end{tabular}

Table 6: Hypomenorrhoea and thyroid dysfunction.

\begin{tabular}{|lllll|}
\hline & Normal cohort & $\begin{array}{l}\text { Thyroid } \\
\text { dysfunction } \\
\text { cohort }\end{array}$ \\
& $\begin{array}{l}\text { No. of } \\
\text { cases }\end{array}$ & $\%$ & $\begin{array}{l}\text { No. of } \\
\text { cases }\end{array}$ & $\%$ \\
\hline Hypomenorrhoea & 4 & 4 & 1 & 9.1 \\
\hline Others & 95 & 96 & 10 & 90.9 \\
\hline
\end{tabular}

Table 5, amenrrhoea presents in $16.2 \%$ of patients of the normal cohort and $9.1 \%$ of patients of the thyroid dysfunction cohort. No statistical significance between amenorrhoea and thyroid dysfunction. Chi-square -0.465 , p-0.9303 not significant.

Table 6, hypomenorrhoea presents in $4 \%$ of the normal cohort and $9.1 \%$ in the thyroid dysfunction cohort. No statistical significance between hypomenorrhoea and thyroid dysfunction. Chi-square-0.415, $\mathrm{p}=0.8$ not significant.

Table 7: Polymenorrhoea and thyroid dysfunction.

\begin{tabular}{|lllll|}
\hline AUB & Normal cohort & $\begin{array}{l}\text { Thyroid } \\
\text { dysfunction } \\
\text { cohort }\end{array}$ \\
\hline $\begin{array}{l}\text { No. of } \\
\text { cases }\end{array}$ & $\%$ & $\begin{array}{l}\text { No. of } \\
\text { cases }\end{array}$ & $\%$ \\
\hline Polymenorrhoea & 5 & 5.1 & 0 & 0 \\
\hline Others & 94 & 94.9 & 11 & 100 \\
\hline
\end{tabular}

Table 8: Uterine size and thyroid dysfunction distribution (USG).

\begin{tabular}{|llcll|}
\hline \multirow{2}{*}{ AUB } & \multicolumn{2}{l}{ Normal cohort } & \multicolumn{2}{l|}{$\begin{array}{l}\text { Thyroid } \\
\text { dysfunction cohort }\end{array}$} \\
& $\begin{array}{l}\text { No. of } \\
\text { cases }\end{array}$ & $\%$ & No. of cases & $\%$ \\
\hline Normal & 67 & 67.7 & 3 & 63.6 \\
\hline Bulky & 32 & 32.3 & 8 & 36.4 \\
\hline
\end{tabular}

Table 7, polymenorrhoea presents in $5.1 \%$ in a normal cohort and no patients in the thyroid dysfunction cohort. No statistical significance exists between thyroid dysfunction and polymenorrhoea. Chi-square - 0.5844, $\mathrm{p}=0.99$ not significant.

Table $8,32.3 \%$ in the normal cohort and $36.4 \%$ in the thyroid dysfunction cohort had a bulky uterus. No statistical association exists between thyroid dysfunction and uterine size. Chi-square $=6.98, \mathrm{p}=0.08$ not significant.

Table 9, the majority of thyroid dysfunction patients are in an upper limit of overweight. There exists a definite significance between thyroid dysfunction and body mass index $\mathrm{p}=0.000<0.001$ significant.

Table 10, in the histopathological examination of endometrium $49.5 \%$ in a normal cohort and $54.5 \%$ thyroid dysfunction cohort reported as proliferative endometrium.

\section{DISCUSSION}

Thyroid enlargement is present in $45.5 \%$ normal cohort and symptoms of thyroid disease in a normal cohort are $1 \%$ and $36.4 \%$ of thyroid dysfunction cohort. ${ }^{7}$ Thyroid enlargement and symptoms of thyroid disease have got 
significant association with thyroid dysfunction. The most common age group studied was between 25-35 years $(55.5 \%)$.

Table 9: BMI and thyroid dysfunction.

\begin{tabular}{|lllll|}
\hline & No. of cases & Mean BMI & Standard deviation & Standard error of mean \\
\hline Normal cohort & 99 & 22.51 & 1.71 & 0.172 \\
\hline Thyroid dysfunction cohort & 11 & 26.95 & 2.891 & 0.872 \\
\hline
\end{tabular}

Table 10: HPE of endometrium distribution in AUB population.

\begin{tabular}{|lllll|}
\hline \multirow{2}{*}{ HPE } & Normal cohort & & \multicolumn{2}{l|}{ Thyroid dysfunction cohort } \\
\hline Anovulatory & No. of cases & Percentage & No. of cases & Percentage \\
\hline Atrophic & 10 & 10.1 & 2 & 18.2 \\
\hline Adenomatous hyperplasia & 1 & 1 & 0 & 0 \\
\hline Cystic hyperplasia & 2 & 2 & 0 & 0 \\
\hline Simple hyperplasia & 2 & 2 & 0 & 0 \\
\hline Secretory & 2 & 2 & 0 & 0 \\
\hline Proliferative & 24 & 24.2 & 2 & 18.2 \\
\hline Ovulatory & 49 & 49.5 & 6 & 54.5 \\
\hline Stromal decidual a synchronization & 2 & 2 & 0 & 0 \\
\hline
\end{tabular}

The present study concludes that there is no significant association between thyroid disorders concerning age group. The majority of thyroid dysfunction $(63.6 \%)$ were in the age group of 25-35 years. Multiparous women (P2L2) constitute the major part of this study $(54.5 \%)$ Most of the women affected by thyroid dysfunction were also multiparous (P2L2). Even though nulliparous women present earlier to gynecology OPD for infertility evaluation, thyroid dysfunction is noted in $9.1 \%$ population in that age group. The most common type of AUB presentation in this study is menorrhagia (43.6\%). ${ }^{8}$ In thyroid dysfunction, menorrhagia constitutes the highest abnormality $(63.6 \%)$ and the least is polymenorrhoea in both groups, AUB patients alone $(5.1 \%)$ and thyroid dysfunction. ${ }^{9}$ This study was against the study Kaur et al which revealed polymenorrhoea prevalence high in hypothyroidism. Thyroid dysfunction is absent in oligomenorrhoea and polymenorrhoea. Next to menorrhagia, menorrhagia constitutes about $18.2 \%$ in the thyroid dysfunction group. There exists no significant association between the episodes of AUB and thyroid dysfunction. ${ }^{10}$ Even though the majority of women attended gynecology OPD in the first episode in the normal cohort is $83.8 \%$ and thyroid dysfunction cohort is $72 . \%$. The majority of women belong to socio-economic class upper-lower, $43.4 \%$ in the normal cohort, and $63.6 \%$ thyroid dysfunction cohort. No significant association is found between thyroid dysfunction and socio-economic status. ${ }^{11}$ A family history of thyroid disorders is present in $18.1 \%$ of thyroid dysfunction. The bulky uterus is present in $32.3 \%$ normal cohort and $36.4 \%$ in the thyroid dysfunction cohort. A significant association was seen between the uterine size and thyroid dysfunction. BMI in thyroid dysfunction group is in the upper limit of the overweight group (mean BMI-26.95) and normal BMI (mean BMI-22.5) in normal cohort BMI, BMI, and thyroid dysfunction have got significant association. The most common endometrial HPE is proliferative in the normal cohort $(49.5 \%)$ and thyroid dysfunction cohort (54.5\%). ${ }^{12,13}$ Endometrial hyperplasia absent in the thyroid dysfunction cohort. The mean duration of AUB in thyroid dysfunction is 7.7 months and in the normal cohort is 5.5 months. The majority of the AUB population presented to the gynecology OPD in the first episode $83.8 \%$ of the cases. ${ }^{14,15}$

\section{CONCLUSION}

Obese people are prone to thyroid dysfunction. In this study thyroid dysfunction, the cohort is in the upper limit of the overweight group $(26.95 \%)$ and normal cohort in normal BMI. The majority of the hypothyroidism patients had proliferative endometrium $(62.5 \%)$ and a minority of patients had secretory endometrium (12.5\%) Clinically thyroid enlarged patients $(45.5 \%)$ and those patients who got symptoms of thyroid disease $(36.4 \%)$ are vulnerable for thyroid disorders. The significant association between abnormal uterine bleeding and thyroid disorder (10\%). It brings into focus the increased incidence of hypothyroidism among women with menorrhagia.

Funding: No funding sources

Conflict of interest: None declared

Ethical approval: The study was approved by the Institutional Ethics Committee 


\section{REFERENCES}

1. Attia AH, Youssef D, Hassan N, El-Meligui M, Kamal M, Al-Inany H. Subclinical hyperthyroidism as a potential factor for dysfunctional uterine bleeding. Gynecol Endocrinol. 2007;23(2):65-8.

2. Association between blood pressure and serum TSH within reference range-population-based study. J Clin Endocrinol Metabol. 2007;92:841-5.

3. Beckmann, Haberette. TSH is associated with insulin resistance independently of body mass index and age in women with the polycystic ovarian syndrome. Oxford J Reprod Med. 2009;24(11):2924-30.

4. Biondi B, Cooper DS. The clinical significance of subclinical thyroid dysfunction. Endocrine Rev. 2008;29(1):76-131.

5. Borna S, Ghanbari Z, Vaghefy T. Menstrual irregularities in thyroid diseases, Imam Hosptial (1999). Tehran Univer Med J TUMS Publications. 2002;60(6):447-52.

6. Doifoide CD, Fernandes K. Study of thyroid dysfunction in patients with DUB. J Obstet Gynecol India. 2001;51(2):93-5.

7. Ito M, Arishima T, Kudo T, Nishihara E, Ohye H, Kubota S, et al. Effect of levo-thyroxine replacement on non-high-density lipoprotein cholesterol in hypothyroid patients. The $\mathrm{J}$ Clin Endocrinol Metabol. 2007;92(2):608-11.

8. Albers J, Hull SK, Wesley RM. Abnormal uterine bleeding. Am Family Phys. 2004;69(8):1915-26.

9. Kakuno Y, Amino N, Kanoh M, Kawai M, Fujiwara M, Kimura $\mathbf{M}$, et al. Menstrual disturbances in various thyroid diseases. Endocrine J. 2010;57(12)1017-22.

10. Kaur T, Aseeja V, Sharma S. Thyroid dysfunction in dysfunctional uterine bleeding. Web Med Central Obstet Gynecol. 2011;2(9):WNCOO2235.

11. Knudsen N, Laurberg P, Rasmussen LB, Bülow I, Perrild H, Ovesen L, Jørgensen T. Small differences in thyroid function may be important for body mass index and the occurrence of obesity in the population. J Clin Endocrinol Metabol. 2005;90(7):4019-24.

12. Poppe K, Velkeniers B, Glinoer D. Thyroid disease and female reproduction. Clin Endocrinol. 2007;66(3):309-21.

13. Lazarus JH, Ammari F, Oretti R, Parkes AB, Richards CJ, Harris B. Clinical aspects of recurrent postpartum thyroiditis. $\mathrm{Br} \mathrm{J}$ General Pract. 1997;47(418):305-8.

14. Sharma N, Sharma A. Thyroid profile in menstrual disorders. JK Sci. 2012;14(1):14.

15. Devrajani BR. Impaired thyroid function in patients with menstrual disturbance (An experience at private clinic). World Appl Sci J. 2010;7(4):538-42.

Cite this article as: Tamilarasi S, Minnalkodi SNS, Prasad G. Thyroid disorders in patients with abnormal uterine bleeding in tertiary care hospital in Chengalpattu district. Int J Reprod Contracept Obstet Gynecol 2020;9:3847-51. 